\title{
STRATEGI PENINGKATAN DAYA SAING PASAR RAKYAT MELALUI PENGEMBANGAN MODEL BISNIS (STUDI KASUS: PLAZA BOGOR)
}

\author{
TRADITIONAL MARKET COMPETITIVENESS IMPROVEMENT STRATEGIES THROUGH \\ THE DEVELOPMENT OF BUSINESS MODELS (CASE STUDY: PLAZA BOGOR)
}

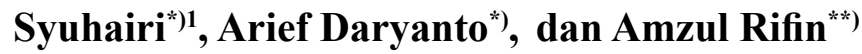 \\ *) Sekolah Bisnis, IPB University \\ Jl. Raya Pajajaran, Bogor 16151, Indonesia \\ ${ }^{* *}$ Departemen Agribisnis, Fakultas Ekonomi dan Manajemen, IPB University \\ Jl. Agatis Kampus IPB Darmaga, Bogor 16680, Indonesia
}

\begin{abstract}
The success of urban markets in the city are increasingly threatened as it continues to grow with the proliferation of spending shopping centers and convenience stores. This study aims to identify, to map the factors that play a role in the business model, to identify the role and influence of stakeholders, to conduct a gap analysis, to analyze the business feasibility of the revitalization program and formulate a business model development strategy. The research method of this paper uses the Business Model Canvas (BMC) as an analysis tool, stakeholder analysis, business feasibility analysis and gap analysis. This study has identified the most interested and influential stakeholder groups. The business feasibility analysis shows that the revitalization program is very feasible because all of the ratio values are in good condition. The strategy that needs to be developed to get the right results is to do several things; 1) develop the more effective business processes. 2) developing the effectiveness of the use of market facilities and infrastructure and 3) improving financial performance and transparency in order to achieve good corporate gouvernance.
\end{abstract}

Keywords: BMC, traditional market, stakeholder analysis, feasibility analysis

\begin{abstract}
Abstrak: Keberhasilan pasar perkotaan di kota semakin terancam karena terus tumbuh dengan proliferasi pusat perbelanjaan dan toko serba ada. Penelitian ini bertujuan mengidentifikasi, memetakan faktor yang berperan dalam model bisnis, mengidentifikasi peran dan pengaruh stakeholder, melakukan analisis kesenjangan, menganalisis kelayakan usaha serta menyusun strategi pengembangan model bisnis. Metoda penelitian menggunakan Business Model Canvas (BMC) sebagai alat analisis, analisis stakeholder, analisis kelayakan usaha dan analisis gap. Penelitian ini berhasil mengidentifikasi kelompok stakeholder yang paling berkepentingan dan berpengaruh. Analisis kelayakan usaha menunjukkan program revitalisasi sangat layak dilakukan karena seluruh nilai rasio menunjukkan kondisi yang baik. Strategi yang perlu dikembangkan untuk mendapatkan hasil yang tepat adalah melakukan beberapa hal; 1) mengembangkan bisnis proses yang lebih efektif. 2) mengembangkan efektivitas pengunaan sarana dan prasana pasar serta 3) meningkatkan kinerja keuangan dan transparasi dalam rangka mencapai good corporate gouvernance.
\end{abstract}

Kata kunci: BMC, pasar rakyat, analisis stakeholder, kelayakan usaha

\footnotetext{
${ }^{1}$ Alamat korespondensi:

Email: syuhairisbipb19@gmail.com
} 


\section{PENDAHULUAN}

Keberadaan pasar rakyat di perkotaan semakin terancam keberadaanya seiring dengan semakin maraknya pembangunan pusat perbelanjaan dan toko swalayan. Adanya penyedia barang dan jasa dengan mutu dan pelayanan yang lebih baik pada konsumen menyebabkan banyak orang mulai beralih ke pusat perbelanjaan dan toko swalayan untuk berbelanja kebutuhan sehari-hari. Disisi lain, daya tarik pasar rakyat semakin menurun akibat buruknya kondisi serta kelengkapan sarana dan prasarana pasar yang rusak, keadaan pasar yang sangat padat dengan penataan barang dagangan yang meluber pada petak jualan, ruang gerak koridor yang sangat terbatas, serta suasana yang sumpek dan kumuh. Apabila hal ini tidak diperhatikan oleh pihak yang berwenang, maka perputaran bisnis di pasar rakyat dapat semakin melambat dan terancam hilang. Perkembangan jumlah pasar rakyat dan pasar modern di Indonesia seperti terlihat pada Gambar 1.

Keberadaan pasar modern dan pasar online semakin melemahkan performa pasar rakyat. Semakin berkurangnya jumlah pasar rakyat dapat berdampak negatif pada perekonomian masyarakat, khususnya kelas menengah ke bawah serta bagi perubahan budaya masyarakat. Melihat peran pentingnya pasar rakyat dalam kehidupan masyarakat, perlu dilakukan berbagai usaha untuk menjaga eksistensinya. Eksistensi pasar rakyat akan bertahan bila manajemen pengelolaannya dilakukan secara profesional (Sulistiyo dan Cahyo, 2010). Salah satu upaya pemerintah yang telah dilakukan adalah menerapkan beberapa peraturan seperti penentuan lokasi pasar rakyat, pengaturan jarak antara pasar modern dengan pasar rakyat. Peraturan tersebut sebagian tertuang dalam Peraturan Presiden Republik Indonesia Nomor 112 Tahun 2007 tentang Penataan dan Pembinaan Sarana Distribusi Bidang Perdagangan, Pusat Perbelanjaan dan Toko Modern, yang menyatakan bahwa Pemerintah dan Pemerintah Daerah baik secara sendiri maupun bersama sesuai dengan tugas masing-masing melakukan penataan, pembinaan dan pengawasan pasar rakyat. Zahratan dan Anggraeni (2015) mengemukakan perkembangan toko modern di Bekasi berdampak pada perubahan seluruh kinerja pedagang pasar rakyat secara signifikan merubah omzet, keuntungan dan jam operasional.

Sementara itu pasar rakyat masih tetap diminati karena karakter/budaya konsumen. Meskipun informasi tentang pola hidup modern dengan mudah diperoleh, namun masyarakat masih memiliki budaya berkunjung dan berbelanja ke pasar rakyat. Upaya riil yang telah dilakukan pemerintah untuk meningkatan daya saing pasar rakyat adalah melakukan revitalisasi pasar. Program revitalisasi pasar bertujuan untuk melakukan renovasi bagi pasar agar kondisi pasar menjadi lebih baik dan mampu bersaing dengan beberapa ritel modern.

Plaza Bogor dengan konsep penggabungan pasar rakyat dan pasar modern telah lama dilakukan oleh PDPPJ untuk meningkatkan daya saing pasar tersebut. Namun demikian, beberapa kios dan toko Plaza Bogor hingga saat ini belum terisi seluruhnya. Tingkat okupansi di Plaza Bogor saat ini mencapai 70\%. Apabila hal tersebut tidak mendapat perhatian dari pengelola maka tingkat okupansi dapat terus menurun dan merugikan PDPPJ selaku pengelola.

Business Model Canvas (BMC) merupakan salah satu alat analisis model bisnis yang cukup komprehensifyang dapat digunakan untuk menggali semua elemen bisnis. Boedianto dan Harjanti (2015), menjelaskan bahwa BMC ditujukan untuk mengetahui implementasi model bisnis yang ada dan mengembangkan strategi bisnis. Selain itu BMC juga ditujukan untuk menganalisa model bisnis dari segmen pelanggan, proposisi nilai, saluran distribusi, hubungan pelanggan untuk meningkatkan penjualan produk dan layanan (Wiska 2016). Menurut Amit dan Zott (2012), memiliki model bisnis yang inovatif dapat menciptakan pasar baru atau memungkinkan perusahaan untuk menciptakan dan memanfaatkan peluang-peluang baru di pasar yang sudah ada. Untuk itu, sebuah model bisnis harus dapat memperlihatkan peluang yang signifikan baik pada saat periode pertumbuhan ekonomi yang pesat maupun pada saat terjadinya gejolak. Model bisnis harus dilakukan melalui pendekatan yang dapat membantu organisasi menghadapi perubahan lingkungan baik internal maupun eksternal. Selain itu, model bisnis harus menjadi sebuah alat yang mudah dipahami dan dapat didesain dan redesain dengan cepat (Soeherman 2014). Salah satu alat yang dapat menggambarkan model bisnis tersebut adalah Business Model Canvas (BMC).

BMC merupakan pendekatan yang mudah dilakukan untuk mengidentifikasi dan mengembangkan komponen penting suatu bisnis dengan membaginya menjadi sembilan elemen dasar, yakni konsumen yang dituju, nilai yang diberikan, saluran yang digunakan, 
cara menjalin hubungan dengan konsumen, aliran pendapatan yang diperoleh, potensi sumber daya yang dimiliki, kegiatan-kegiatan inti yang harus dilakukan, mitra kunci yang dapat membantu dan perkiraan biaya yang harus dikeluarkan. Penggunaan BMC untuk melakukan re-inovasi pasar rakyat diharapkan dapat meningkatkan daya saing untuk menghadapai persaingan.

Terdapat beberapa penelitian terdahulu yang menjadi acuan dalam penelitian ini. Kajian pertama dilakukan oleh Khairunnisa (2018) menyimpulkan bahwa PDPPJ dalam hal ini perlu memberi perhatian khusus terutama pada elemen key activities dan key resource, mengembangkan strategi melakukan revitalisasi total terhadap sumber daya fisik perusahaan. Bakri (2011) menyimpulkan bahwa peningkatan kualitas pelayanan, peningkatan sarana prasarana dan pengaturan PKL pasar perlu dilakukan untuk meningkatkan posisi tawar. Suryadarma (2007) menyimpulkan untuk menjamin keberlangsungan pasar rakyat diperlukan perbaikan sistem pengelolaan pasar rakyat yang memungkinkan dapat bersaing dan tetap bertahan bersama kehadiran supermarket. Shody (2019) menyimpulkan revitalisasi merupakan hal penting yang perlu diambil pemerintah dalam rangka mempertahankan eksistensi pasar rakyat. Viali (2018) menyimpulkan bahwa BMC dapat dijadikan dasar membuat strategi dan program kerja untuk meningkatkan kinerja perusahaan.

Keberhasilan peningkatan daya saing Plaza Bogor melalui pengembangan model bisnis diharapkan dapat menjadi percontohan untuk pasar lainnya di Indonesia, khususnya di Kota Bogor. Tujuan penelitian ini adalah (1) mengidentifikasi, memetakkan faktor kunci yang berperan dalam model bisnis Plaza Bogor, (2) mengidentifikasi peran dan pengaruh stakeholder terhadap pengelolaan Plaza Bogor, (3) melakukan analisis kelayakan usaha kegiatan revitalisasi Plaza Bogor, (4) melakukan analisis kesenjangan dalam rangka mendapatkan model bisnis perbaikan untuk Plaza Bogor, kemudian (5) menyusun strategi pengembangan model bisnis untuk meningkatkan daya saing Plaza Bogor.

Penelitian ini difokuskan pada kegiatan bisnis di Plaza Bogor. Ruang lingkup penelitian meliputi keragaan model bisnis yang ada saat ini termasuk pada faktor-faktor lingkungan yang berpengaruh, analisis stakeholder yang terlibat, analisis kelayakan usaha program revitalisasi, analisis gap dan pembuatan desain pengembangan model bisnis baru sebagai upaya untuk meningkatkan daya saing Plaza Bogor.

\section{METODE PENELITIAN}

Penelitian ini dilakukan di Plaza Bogor yang berada di Jalan Suryakencana, Kelurahan Babakan Pasar, Kecamatan Bogor Tengah. Penelitian dilaksanakan mulai dari bulan Maret - Juli 2019. Penelitian ini menggunakan data primer dan sekunder. Data primer diperoleh dari hasil observasi/pengamatan langsung, dan wawancara dengan manajemen PDPPJ, dan wawancara pada ahli/pakar untuk mendapatkan informasi, pendapat, kebijakan, dan pertimbangan mengenai permasalahan, kondisi, peluang dan ancaman yang dihadapi Plaza Bogor. Sementara itu, data sekunder diperoleh dengan mengakses informasi/data dari manajemen dan instansi terkait seperti Badan Pusat Statistik, Kementerian Perdagangan, Kementerian Perindustrian, dan sumber data lainnya yang relevan dengan topik penelitian seeprti jurnal ilmiah, buku, working paper, proceeding, dan yang lainnya.

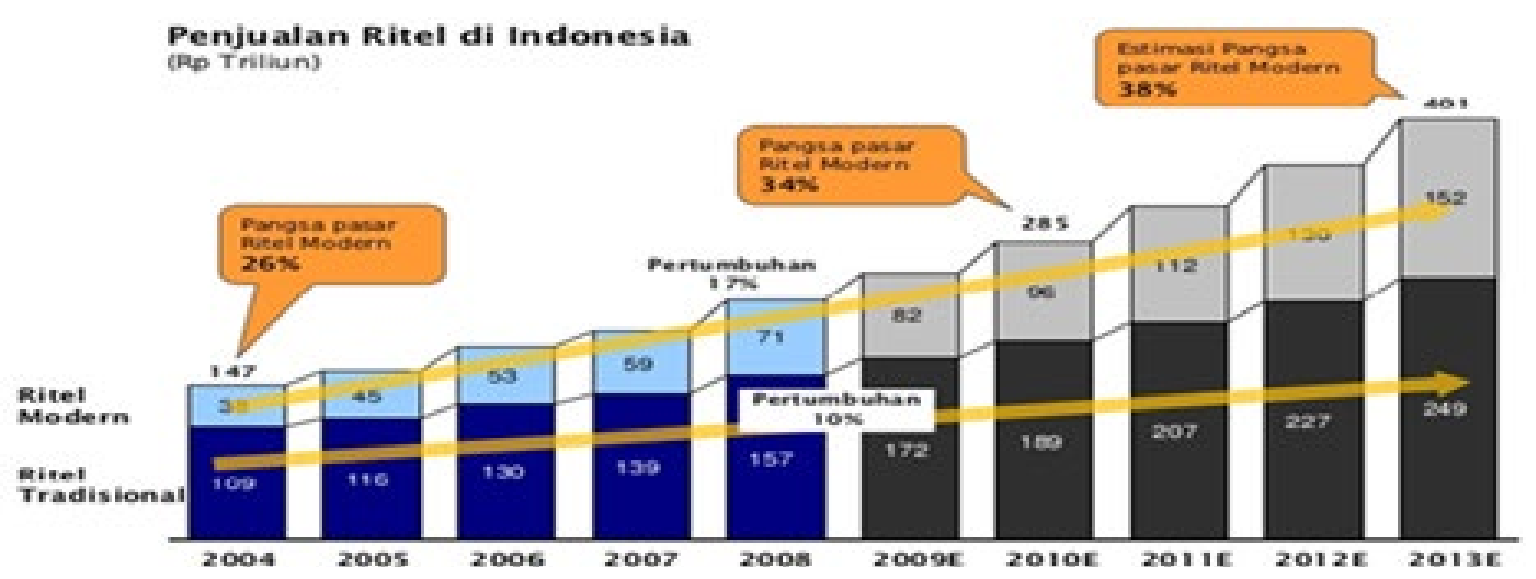

Gambar 1. Perbandingan pertumbuhan pasar rakyat dan pasar modern 
Pengambilan contoh dilakukan dengan menggunakan teknik non-probability sampling (contoh tanpa peluang) yakni penentuan responden secara sengaja (purposive sampling) melalui pendekatan expertise judgment. Judgment sampling menurut Juanda (2009) adalah prosedur dalam memilih contoh berdasarkan pertimbangan tentang karakteristik yang cocok berkaitan dengan anggota contoh yang diperlukan untuk menjawab tujuan penelitian. Pada prosesnya, responden ahli dari pihak manajemen dipilih sebanyak tiga orang. Daftar responden dalam penelitian ini dapat dilihat pada Tabel 1.

Tabel 1. Daftar responden

\begin{tabular}{|c|c|}
\hline Posisi & Analisis \\
\hline $\begin{array}{l}\text { Direktur Utama } \\
\text { PDPPJ }\end{array}$ & BMC, B/C Ratio, Analisis Gap \\
\hline $\begin{array}{l}\text { Direktur Umum } \\
\text { PDPPJ }\end{array}$ & BMC, B/C Ratio, Analisis Gap \\
\hline $\begin{array}{l}\text { Direktur } \\
\text { Operasional PDPPJ }\end{array}$ & BMC, B/C Ratio, Analisis Gap \\
\hline $\begin{array}{l}\text { Ketua Asosiasi } \\
\text { Pedagang }\end{array}$ & Analisis Stakeholder, Analisis Gap \\
\hline Akademisi & Analisis Stakeholder, Analisis Gap \\
\hline Pemerintah Kota & Analisis Stakeholder, Analisis Gap \\
\hline Pengamat & Analisis Stakeholderr, Analisis Gap \\
\hline $\begin{array}{l}\text { Lembaga Swadaya } \\
\text { Masyarakat }\end{array}$ & Analisis Stakeholder, Analisis Gap \\
\hline
\end{tabular}

Metode utama yang digunakan untuk meningkatkan daya saing Plaza Bogor dalam penelitian ini adalah Business Model. Alat analisis yang digunakan adalah Business Model Canvas (BMC), Analisis Stakeholder, Analisis B/C Ratio dan Analisis Gap. Tahapan pengolahan dan analisis data yang dilakukan meliputi: Analisis Deskriptif (Analisis deskriptif dilakukan untuk mendapatkan gambaran umum secara menyeluruh mengenai hal-hal yang berkaitan dengan objek penelitian dengan pendekatan nonstatistik); Pemetaan dan Identifikasi Model Bisnis (Pemetaan dan identifikasi model bisnis dimulai dengan mengidentifikasikan sembilan elemen BMC); Analisis Stakeholder (Mitchell et al. (1997) menjelaskan stakeholder dalam arti luas merupakan individu atau kelompok yang mampu mempengaruhi pencapaian tujuan perusahaan dan memiliki hubungan yang saling berkorelasi. Sedangkan dalam arti sempit, stakeholder adalah pihak-pihak yang menguntungkan dirinya untuk menjamin kelangsungan perusahaan); Analisis $B / C$ Ratio (Tingkat efisiensi pengelolaan
Plaza Bogor dapat diukur melalui besarnya rasio keuntungan terhadap biaya operasional dan investasi. Rasio keuntungan dan biaya pengelolaan digunakan untuk mengetahui besarnya keuntungan yang diterima atas biaya operasional yang dikeluarkan PD Pasar Pakuan Jaya); Analisis Gap (Analisis stakeholder dapat diawali dengan mengidentifikasi semua stakeholder yang terlibat/memiliki hubungan dengan Plaza Bogor, baik secara langsung maupun tidak langsung. Hasil identifikasi kemudian dipetakan dalam bentuk sebuah matriks (Mapping Matrix)); Pengembangan Model Bisnis (Strategi pengembangan dilakukan setelah mengetahui hasil evaluasi model bisnis berdasarkan analisis gap dengan didukung analisis stakeholder dan analisis B/C Ratio. Ketiganya kemudian menjadi pedoman dasar untuk mengembangan desain perbaikan dan pengembangan elemen-elemen model Plaza Bogor dalam rangka menjaga keberlanjutan usaha di Plaza Bogor (viability) melalui peningkatan daya saing).

Konsep strategi peningkatan daya saing, produktivitas dan efisiensi Plaza Bogor menggunakan alat analisis Business Model Canvas (BMC) untuk memetakan secara rinci ke dalam sembilan blok kunci yang saling berhubungan dan memuat aspek-aspek penting sebuah bisnis. Hasil pemetaan sembilan blok kemudian dievaluasi dengan menggunakan analisis Gap. Hal ini dilakukan untuk memodifikasi elemen-elemen model bisnis yang telah dipetakkan sebelumnya. Dari hasil modifikasi yang diperoleh kemudian dibuat implikasi manajerial (implikasi kebijakan) sebagai bentuk saran dan tindakan yang harus dilakukan pengelola Plaza Bogor dalam menjalankan strategi yang telah dirumuskan. Mengingat Plaza Bogor merupakan entitas bisnis yang dipengaruhi oleh banyak pihak (stakeholder), maka kajian juga diperdalam pada blok bisnis Key Partnership melalui analisis stakeholder. Sementara ntuk analisis efisiensi biaya diperdalam pada blok Cost Structure dengan melakukan analisis $B / C$ Ratio. Analisis stakeholder dan program revitalisasi dilakukan secara paralel karena menurut Aini et al. (2019) di beberapa daerah program revitalisasi sering menimbulkan kontroversi, dari itu perlu dilakukan analisis stakeholder untuk menentukan tingkat keterlibatan, minat dan pengaruh semua stakeholder. Secara keseluruhan sistematika penelitian dituangkan pada kerangka pemikiran penelitian yang digambarkan pada Gambar 2. 


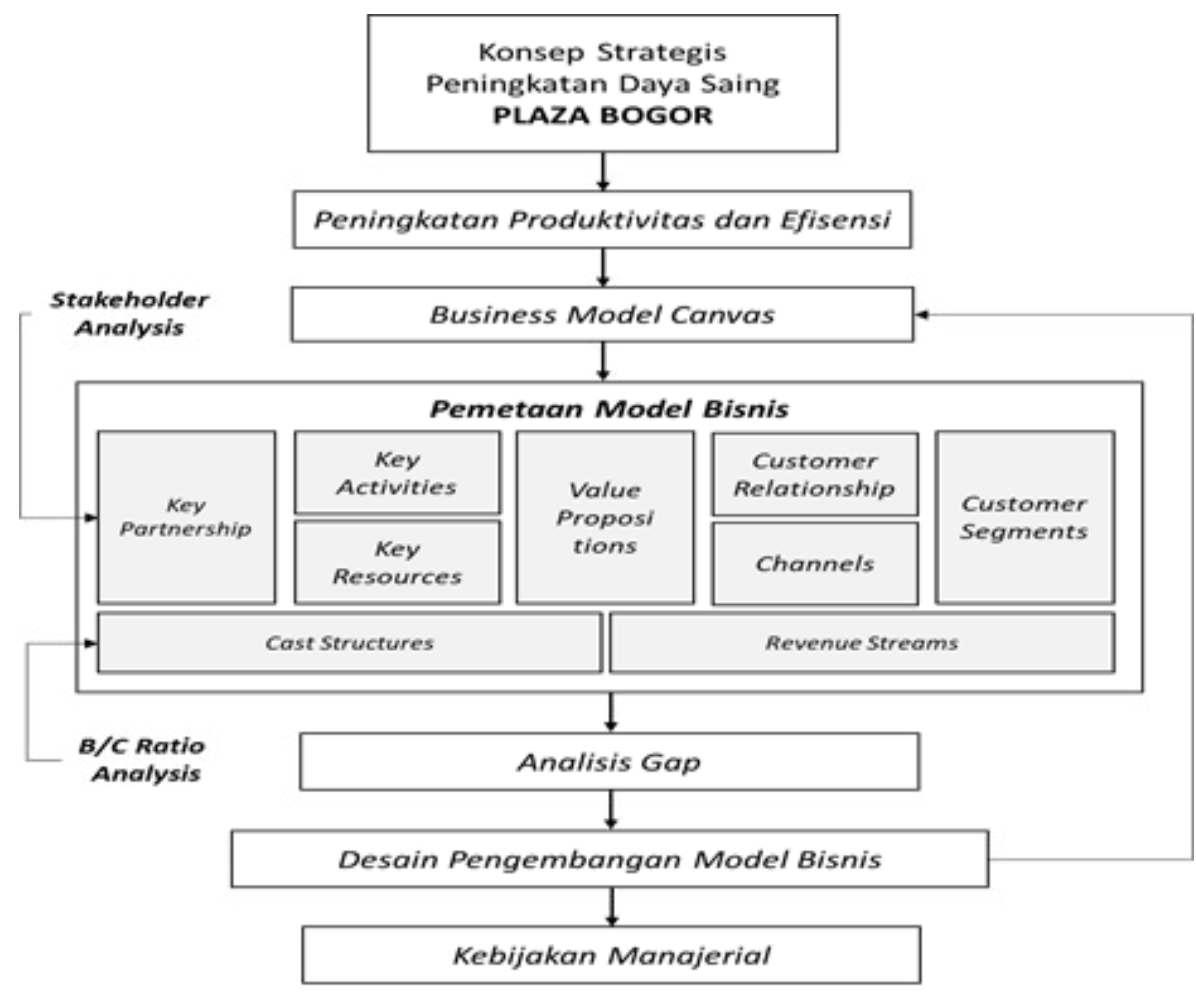

Gambar 2. Kerangka pemikiran penelitian

\section{HASIL}

\section{Pemetaan Model Bisnis Plaza Bogor}

Pemetaan model bisnis dilakukan untuk memperoleh gambaran dan informasi yang mendalam pada model bisnis yang dijalankan perusahaan. Berdasarkan hasil FGD dengan manajemen Plaza Bogor maka model bisnis perusahaan tersebut dapat dipetakkan pada Gambar 3 yang menjelaskan kondisi existing dari Plaza Bogor. Kondisi ini masih dirasa memerlukan perbaikan untuk meningkatkan kinerja serta menjaga keberlanjutan dari bisnis yang dijalankan.

\section{Analisis Stakeholder}

Analisis Stakeholder dilakukan untuk menunjukkan instansi terkait dalam perencanaan dan pelaksanaan kebijakan pengembangan Plaza Bogor diperlukan perbaikan dalam kebijakan yang ada saat ini dengan menyesuaikan pada kondisi yang ada (Puspatara dan Putu, 2015). Penggolongan stakeholder didasarkan pada tingkat kepentingan terhadap pengembangan dan revitalisasi Plaza Bogor. Kegiatan revitalisasi dan pengelolaan Plaza Bogor melibatkan 13 stakeholder yang berasal dari berbagai instansi diantaranya: Pemerintah Daerah Kota Bogor, Badan Usaha Milik Daerah (BUMD), lembaga swasta, dan lembaga masyarakat. Tabel 2 memberikan indentifikasi awal terkait golongan dari tiap stakeholder. Hal ini perlu dilanjutkan dengan memetakan dalam sebuah matriks seperti Gambar 5.

\section{Analisis Kelayakan Usaha}

Analisis kriteria kelayakan usaha dilakukan untuk menentukan apakah unit usaha Plaza Bogor layak untuk diusahakan selama umur proyek selama lima tahun. (Solihin, 2015; Aswara et al. 2017) mengemukakan bahwa NPV, IRR dan B/C rasio dapat digunakan untuk menganalisa kelayakan usaha revitalisasi pasar. Dalam penelitian ini Analisis kriteria kelayakan menggunakan empat kriteria, yaitu Net Present Value (NPV), Net B/C, Internal Rate of Return (IRR) dan Discounted Payback Period dapat dilihat pada Tabel 3.

Net Present Value (NPV) suatu proyek adalah selisih PV pada penerimaan dengan PV pada arus biaya, dengan kata lain manfaat bersih yang diperoleh selama periode usaha. Berdasarkan hasil perhitungan, diperoleh nilai NPV sebesar Rp19.588.387.929. nilai tersebut menunjukkan bahwa arus masuk selama periode lima tahun (karena tidak dilakukan pembangunan, hanya revitalisasi saja) dengan tingkat suku Bunga 12\% lebih besar dari pada arus kas keluarnya. Hal ini menandakan bahwa revitalisasi Plaza Bogor yang akan dilakukan menguntungkan dan layak untuk diimplementasikan atau dijalankan dalam jangka panjang karena NPV 
lebih besar dari nol. Pada dasarnya NPV merupakan cara yang baik dan tepat untuk memandang sebuah aktifitas investasi yang dilakukan, namun dalam hal ini penghitung kelayakan perlu menyesuaikan tingkat suku bunga terbaik yang digunakan (Jory et al. 2016).

B/C Ratio digunakan untuk melihat manfaat bersih tambahan, dengan kata lain nilai bersih saat ini yang diterima oleh suatu bisnis selama umur bisnis tersebut pada tingkat suku bunga tertentu. Suatu proyek dinyatakan layak jika nilainya $>1$ sedangkan jika nilainya $<$ dari satu maka proyek tersebut tidak layak dijalankan. Berdasarkan Tabel 3 diperoleh B/C Ratio revitalisasi Plaza Bogor sebesar 1.58. Nilai tersebut menunjukkan bahwa setiap penambahan Rp1 biaya maka akan menghasilkan keuntungan sebesar Rp1,580 sehingga revitasisasi Plaza Bogor layak untuk dijalankan dan dilaksanakan. Adi etal. (2016) menjelaskan bahwa balanced cost ratio dengan nilai lebih satu menandakan bahwa aktifitas yang dilakukan dapat memberikan hasil yang lebih tinggi dari pada biaya yang dikeluarkan.

Internal Rate of Return (IRR) digunakan untuk mengetahui kemampuan suatu proyek untuk menghasilkan tingkat pengembalian modal bagi perusahaan yang melakukan investasi selama proyek berlangsung dan dinyatakan dalam satuan persen. Berdasarkan hasil olah data diperoleh hasil IRR sebesar $81.82 \%$. Hasil ini menunjukkan bahwa tingkat pengembalian proyek terhadap investasi yang dilakukan sebesar 98 persen. Hal ini menunjukkan bahwa kemampuan dalam pengembalian modal yang digunakan lebih besar dari discount rate yang digunakan, dengan demikian revitalisasi Plaza Bogor layak untuk dilaksanakan. Rokhmawati (2019) menjelaskan bahwa nilai interest rate ratio yang tinggi maka semakin aman untuk mengembangkan perusahaan.

\begin{tabular}{|c|c|c|c|c|}
\hline \multirow{2}{*}{$\begin{array}{l}\text { Fey Paburs } \\
\text { - Mitra parkir } \\
\text { - Pemerintah } \\
\text { - Anggota dewan } \\
\text { - Kelompok } \\
\text { pedagang } \\
\text { - Media massa } \\
\text { - Lembaga } \\
\text { swadaya } \\
\text { masyarakat } \\
\text { - Aktifitas } \\
\text { mahasiswa }\end{array}$} & $\begin{array}{l}\text { Key Activities } \\
\text { - Penagihan biaya } \\
\text { - Komunikasi }\end{array}$ & \multirow{2}{*}{$\begin{array}{l}\text { Value } \\
\text { Propotition } \\
\text { - Lokasi } \\
\text { strategi di } \\
\text { tengah kota } \\
\text { - Pelayanan } \\
\text { semi matl } \\
\text { - Dilewati rute } \\
\text { anghutan } \\
\text { umum } \\
\text { - Berselabahan } \\
\text { dengan pasar } \\
\text { basah } \\
\end{array}$} & $\begin{array}{l}\text { Custmer } \\
\text { Relationship } \\
\text { - Layanan } \\
\text { personal } \\
\text { (komunikasi } \\
\text { formal dan } \\
\text { informal) }\end{array}$ & \multirow[t]{2}{*}{$\begin{array}{l}\text { Customer } \\
\text { Segments } \\
\text { - Pedangan } \\
\text { ritel } \\
\text { modem } \\
\text { - Pedangan } \\
\text { traditional }\end{array}$} \\
\hline & $\begin{array}{l}\text { Fey Resources } \\
\text { - Sumberdaya fisik } \\
\text { (gedung dan } \\
\text { fasilitas) } \\
\text { - Sumberdaya } \\
\text { manusia }\end{array}$ & & $\begin{array}{l}\text { Channels } \\
\text { - Tenaga } \\
\text { penjualan } \\
\text { langsung }\end{array}$ & \\
\hline \multicolumn{2}{|l|}{$\begin{array}{l}\text { Cost stream } \\
\text { - Gaji pegawai } \\
\text { - Biaya perawatan }\end{array}$} & \multicolumn{2}{|c|}{\begin{tabular}{l|l} 
& Revene u stream \\
& - Sew a kios \\
- Pendapatan kebersihan & Pendapatan keamanan
\end{tabular}} & \\
\hline
\end{tabular}

Gambar 3. Model bisnis Plaza Bogor

Tabel 2 Identifikasi Stakeholder

\begin{tabular}{ll}
\hline Nama & Keterangan \\
\hline Walikota Bogor & Pemerintah Daerah \\
DPRD Kota Bogor & Pemerintah Daerah \\
LPSE & Pemerintah Daerah \\
Kelurahan Lebak Pasar & Pemerintah Daerah \\
PD. Pasar Pakuan Jaya & BUMD Kota Bogor \\
Kota Bogor & \\
Perusahaan Mitra Kerja & Lembaga swasta \\
Sama & \\
Perusahaan Supplier & Lembaga swasta \\
\hline
\end{tabular}

\begin{tabular}{ll}
\hline Nama & Keterangan \\
\hline Media Massa & Lembaga swasta \\
Konsultan perencana & Lembaga swasta \\
Kontraktor Pelaksana & Lembaga swasta \\
Paguyuban pedagang Plaza & Lembaga Masyarakat \\
Bogor & \\
Lembaga Swadaya & Lembaga Masyarakat \\
$\begin{array}{l}\text { Masyarakat (LSM) } \\
\text { Masyarakat sekitar plaza } \\
\text { Bogor }\end{array}$ & Masyarakat \\
\hline
\end{tabular}




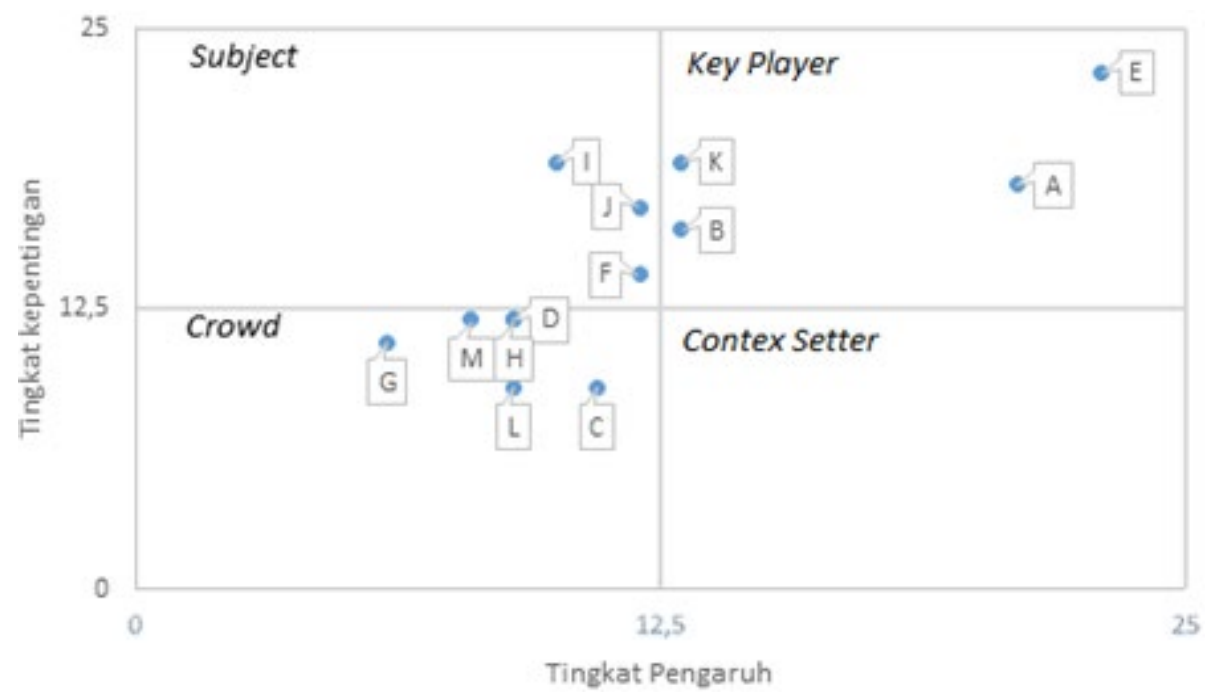

Gambar 4. Peta Stakeholder Dalam Pengelolaan Plaza Bogor $(A=$ Walikota, $B=$ DPRD Kota, $C=$ LPSE, $D=$ Kel. Lebak Pasar, $\mathrm{E}=$ PD.PPJ $\mathrm{F}=$ Perus Kerjasama, $\mathrm{G}=$ Supplier, $\mathrm{H}=$ Media Massa $\mathrm{I}=$ Konsultan Perencana, $\mathrm{J}=$ Kontraktor Pelaksana, $\mathrm{K}=$ Paguyuban Pedagang, $\mathrm{L}=\mathrm{LSM}, \mathrm{M}=$ Masyarakat Sekitar Lb Pasar)

Tabel 3 Hasil kriteria kelayakan usaha

\begin{tabular}{lr}
\hline Kriteria investasi & \multicolumn{1}{l}{ Nilai } \\
\hline NPV (Rp) & 19.588 .387 .829 \\
B/C & 1,58 \\
IRR & 81,82 \\
DPP & 1,50 \\
\hline
\end{tabular}

\section{Discounted Payback period (DPP) digunakan} untuk melihat jangka waktu pengembalian modal dengan mengembalikan biaya investasi awal dengan memperhitungkan present value dan discont factor di masa yang akan datang DPP revitalisasi Plaza Bogor, yakni selama 1,5 tahun, artinya tingkat pengembalian investasi dibawah jangka waktu dua tahun. Hal ini berarti nilainya lebih rendah dibandingkan dengan umur poyek, dengan demikian revitalisasi Plaza Bogor sangat layak untuk dilaksanakan. Sidauruk et al. (2018) menjelaskan mengambarkan mengenai jangka waktu pengembalian investasi, semakin pendek waktu pengembalian maka semakin mampu mengambarkan kelayakan usaha.

\section{Rumusan Model Canvas Perbaikan}

Nurhakimetal.(2018)mengemukakan bahwa perbaikan model bisnis perlu dilakukan untuk pengembangan organisasi kedepan disaat model bisnis eksisting dirasa kurang maksimal. Perbaikan business model canvas diketahui memerlukan desain bisnis model canvas plaza bogor. Pendekatan analisis kesenjangan menggunakan pendapat para ahli yang mengacu dari logical thinking process. Detmer (2007) menjelaskan bahwa logical thinking process merupakan suatu cara yang efektif dan sistematis untuk merencanakan, mengevaluasi serta membuat koreksi yang dibutuhkan dalam waktu yang singkat. Hasil masukan yang diberikan oleh pakar dijadikan dasar untuk menyusun perbaikan business model canvas yang baru.

Gambar 5 menunjukan hasil perbaikan atas analisa kondisi business model canvas (existing), analis stakeholder dan analisis benefit cost ratio yang dirangkum oleh para pakar menjadi model baru, dimana model tersebut akan menjadi dasar untuk menyusun strategi peningkatan daya saing dalam mengelola Plaza Bogor. Terdapat beberapa strategi yang dapat ditawarkan kepada manajemen dalam rangka meningkatkan performance dari manajemen, pendekatan yang digunakan dalam memberikan rekomendasi strategi menggunakan pendekatan 4 disiplines execution (Covey et al. 2012) yaitu sebagai berikut:

\section{Mengembangkan bisnis proses yang lebih efektif}

Business model canves perbaikan memberikan gambaran terkait dengan beberapa aktifitas yang perlu dilakukan oleh manajemen dalam rangka mencapai tujuan yang telah ditetapkan. Saat ini manajemen perlu melakukan pendekatan khususnya kepada 
pemerintah untuk membantu bisnis yang dijalankan serta upaya untuk melindungi pasar rakyat. Selain manajemen juga perlu untuk melakukan komunikasi dan promosi kepada stakeholder internal dimana untuk meningkatkan kunjungan pembeli, mendorong penggunaan sosial media dan teknologi digital dalam melakukan transaksi. Menurut Fatmala et al. (2019) perubahan teknologi akan mendorong perusahaan lebih efisien dan produktif, serta memasarkan space iklan di kawasan Plaza Bogor.

2. Mengembangkan efektivitas pengunaan sarana dan prasana

Perusahaan menyadari bahwa saat ini penggunaan space masih belum efektif karena tata ruang yang kurang tepat. Dalam hal ini, melalui kegiatan revitalisasi harus segera diperbaiki untuk mencapai efektifitas penggunaan sarana dan prasana dengan cara redesign tata ruang. Fenomena revitalisasi pasar rakyat sudah mulai diterima sebagian masyarakat karena kegiatan belanja menjadi lebih efisien (Sudjono, 2014). Strategi ini diharapkan akan memberikan dampak pada peningkatan pemasukan keuangan perusahaan serta kenyamanan pelanggan.
3. Meningkatkan kinerja keuangan dan transparasi dalam rangka mencapai good corporate gouvernance

Manajemen perlu meningkatan serta mempertahankan transparansi dalam keuangan hal ini ditujukan agar setiap pengeluaran dapat tercatat, diaudit dan dipertanggungjawabkan kepada stakeholder yang berwenang. Manajemen menyadari bahwa akan terdapat pemasukan yang bersumber dari pendapatan space iklan.

\section{Implikasi Manajerial}

\section{Stakeholder}

Pengelolaan untuk meningkatkan daya saing memiliki tantangan yang besar dimana manajemen Plaza Bogor harus mampu menjaga hubungan dengan baik seluruh stakeholder yang terlibat dalam bisnis yang dijalankan, dimana menjaga hal ini dapat dilakukan dengan mengacu pada prinsip good gouvenance. Dampaknya manajemen akan semakin dipercaya oleh para stakeholder lainnya karena dianggap capable untuk mengelola pasar rakyat menjadi lebih baik.

\begin{tabular}{|c|c|c|c|c|}
\hline \multirow{2}{*}{$\begin{array}{l}\text { Key Pubuers } \\
\text { - Mitra parkir } \\
\text { - Pemerintah } \\
\text { - Anggota } \\
\text { dewan } \\
\text { - Kelompok } \\
\text { pedagang } \\
\text { - Media massa } \\
\text { - Lembagg } \\
\text { gwadaya } \\
\text { masyaralat } \\
\text { - Aktifitas } \\
\text { mahasiswa }\end{array}$} & $\begin{array}{l}\text { Key Activites } \\
\text { - Penagihan biaya } \\
\text { - Komunikasi } \\
\text { - Inisiasike penerintah* } \\
\text { - Promosi ke lingungan } \\
\text { eksternal* } \\
\text { - Melakukan revitalisasi } \\
\text { tata nuang* }\end{array}$ & \multirow{2}{*}{$\begin{array}{l}\text { Vahue Propotition } \\
\text { - Lokasi strategi di } \\
\text { tengahkota } \\
\text { - Pelayanansemi } \\
\text { mall } \\
\text { - Dilewatinte } \\
\text { angkutanumum } \\
\text { - Berselabahan } \\
\text { dengan paser } \\
\text { basah } \\
\text { - Jaminan perbaikan } \\
\text { atauperawatan } \\
\text { untuk tok* } \\
\text { - Jaminan } \\
\text { kebersihan* }\end{array}$} & $\begin{array}{l}\text { Custamer } \\
\text { Relationship } \\
\text { - Layanan } \\
\text { personal } \\
\text { (komuritasi } \\
\text { formal dan } \\
\text { irformal) } \\
\text { - Pengrumaan } \\
\text { aplifasi* } \\
\end{array}$ & \multirow[t]{2}{*}{$\begin{array}{l}\text { Custamer } \\
\text { Segments } \\
\text { - Pedangen } \\
\text { ritel } \\
\text { modem } \\
\text { - Pedangen } \\
\text { traditional } \\
\text { - Distributor } \\
\text { - Vendor } \\
\text { iklan * }\end{array}$} \\
\hline & $\begin{array}{l}\text { Key Resources } \\
\text { - Sumberdaya fisik } \\
\text { (gedung den fasilitas) } \\
\text { - Sumberdaya manusia } \\
\text { - Dutungan pemerintah* } \\
\text { - Meciapotvey } \\
\text { engagement* } \\
\end{array}$ & & $\begin{array}{l}\text { Chavrels } \\
\text { - Teraga } \\
\text { penjulan } \\
\text { langsung } \\
\text { - Socical mediot }\end{array}$ & \\
\hline \multicolumn{2}{|c|}{$\begin{array}{l}\text { Coststrean } \\
\text { - Gaji pegawai } \\
\text { - Biaya perawatan } \\
\text { - Biaya pengelolaan pasa* } \\
\text { - Biaya administrasi umum* } \\
\text { - Biaya peryusutan* }\end{array}$} & \multicolumn{3}{|c|}{$\begin{array}{l}\text { Reveneu stream } \\
\text { - Sewa kios } \\
\text { - Servis charges } \\
\text { - Pendapatan kebersihan } \\
\text { - Pendapatan keamanan } \\
\text { - Pendapatan parkir dan bongkar muat } \\
\text { - Pendapatan iklan* } \\
\text { - Pendapatan pengoldaan listrik, air dan gas* }\end{array}$} \\
\hline
\end{tabular}

Gambar 5. Business Model Canvas Perbaikan 


\section{Pendapatan dan Pengeluaran}

Pendapatan dan pengeluaran perusahaan dipandang sebagai suatu dampak akhir yang memiliki peran untuk menjaga keberlanjutan bisnis perusahaan. Manajemen mengetahui bahwa saat ini kelayakan usaha telah memenuhi syarat maka dari itu, kondisi yang terjadi harus dipertahankan agar tetap memiliki nilai rasio yang baik. Selain dalam mempertahankan perlu didukung oleh langkah starategis yang baik sebagai acuan dalam perencanaan dan menyusun implementasi yang tepat.

\section{Business model Canvas Plaza Bogor}

Hasil perbaikan menunjukan bahwa saat ini manajemen perlu menambahkan beberapa point penting pada business model canvas. Output dari business model canvas nantinya akan dijadikan sebagai visualisasi kondisi bisnis Plaza Bogor selama beberapa waktu. Dampaknya dengan mengetahui hal ini adalah manajemen akan berkoordinasi mengenai issue-issue penting dalam mengembangkan bisnis yang dijalankan

\section{KESIMPULAN DAN SARAN}

\section{Kesimpulan}

Pada penelitian ini diketahui terdapat beberapa kesimpulan yang sesuai dengan tujuan penelitian, dimana hasil identifikasi faktor kunci yang berperan dalam model bisnis Plaza Bogor dapat diketahui dengan business model canvas. Dimana dketahui terdapat sembilan blok yang didalamnya terdapat informasi faktor yang berperan dalam bisnis Plaza Bogor. Stakeholder atau aktor yang terlibat merupakan bagian penting baik pada stakeholder yang terlibat langsung maupun tidak langsung. Hasil identifikasi menemukan 13 stakeholder yang memiliki pengaruh dan kepentingan yang berbedaAnalisa kelayakan usaha yang revitalisasi Plaza Bogor terbukti layak. Temuan ini didukung dengan perhitungan dari beberapa indicator kelayakan usaha seperti net present value yang berada diangka positif, benefit cost yang memiliki nilai lebih dari satu dan interest rate ratio yang memiliki besaran lebih dari discount factor yang digunakan. Hal ini menanadakan bahwa revitalisasi Plaza Bogor menjadi hal yang profitable untuk diimplementasikan oleh manajemen.
Hasil analisa kesenjangan menyimpulkan beberapa faktor yang perlu ditambahkan dalam business model canvas perbaikan adalah jaminan perbaikan/perawatan gedung, jaminan kebersihan, layanan yang lebih baik, mendorong penggunaan media sosial, membangun sistem pengelolaan berbasis teknologi, meningkatkan penjualan iklan, memperoleh dukungan pemerintah kota menerbitkan peraturan, meningkatkan komunikasi dengan pengelola media, melakukan promosi ke lingkungan eksternal, meningkatkan komunikasi dengan pedagang, menghitung biaya pengelolaan dan penyusutan secara benar sesuai aturan standar akuntansi Straegi yang perlu dikembangkan oleh manajemen untuk mendapatkan hasil yang tepat adalah melakukan beberapa alternatif yang telah disusun, yaitu 1) mengembangkan bisnis proses yang lebih efektif; 2) mengembangkan efektifitas pengunaan sarana dan prasana; 3) meningkatkan kinerja keuangan dan transparasi dalam rangka mencapai good corporate gouvernance.

\section{Saran}

Pada kajian ini ditemukan beberapa alternatif penting yang harus dilakukan yaitu manajemen perlu membuat action plan yang sesuai untuk mengimplementasikan strategi yang telah disusun. Hal ini dapat dilakukan dengan konsep people process dan tools. Menyelaraskan komunikasi kepada stakeholder lainya guna mendapatkan kepercayaan yang lebih baik. Penelitian selanjutnya sebaiknya merujuk kepada pengembangan model pengelolaan pasar rakyat diera industri digital.

\section{DAFTAR PUSTAKA}

Adi AP, Handayani FS, Setiono. 2016. Analisis kelayakan investasi dan optimalisasi komposisi jumlah tipe rumah untuk mendapatkan keuntungan optimum pada perumnas Jeruk Sawit Permai Karanganyar. Ejurnal Matriks Teknik Sipil 1(1):1-6.

Aini DN, Fauzi HM, Muchtar H. 2019. Analisis kebijakan dan strategi pengembangan pasar tradisional di Kabupaten Situbondo. CERMIN: Jurnal Penelitian 3(2):142-157.

Amit R, Zott C. 2012. Creating value through business model innovation. Journal MIT Sloan Management Review 53(3): 41-49.

Aswara D, Tiaramita N, Hermawan F, Kistiani F. 2017. Perbandingan investasi revitalisasi bangunan 
pasar tradisional di Kota Semarang. Jurnal Karya Teknik Sipil 6(2): 133-144.

Bakri M. 2011. Strategi Peningkatan Posisi Tawar Pasar Tradisional Terhadap pedagang di Kota Bogor [tesis]. Bogor: Institut Pertanian Bogor.

Boedianto, Harjanti D. 2015. Pengembangan Bisnis Pada Depot Selaris Dengan Pendekatan Business Model Canvas (BMC). Agora 3(2): 292-301.

Covey S, McChesney $\mathrm{C}$, Huling J. 2012. The 4 Disciplines of Execution. Jakarta: Dunamis.

Dettmer, H. W. (2007). The Logical Thinking Process: a Systems Approach to Complex Problem Solving. Milwaukee, Wiscosin: ASQ Quality Press.

Fatmala E, Hakim DB, Anggraeni L. 2019. Efisiensi dan Produktivitas Perbankan Sebelum dan Setelah Krisis Keuangan. Jurnal Aplikasi Bisnis Dan Manajemen (JABM) 5(2): 200.

Giesen E, Riddleberger E, Christer R, Bell R. 2010. When and How to Innovate Your Business Model. Journal of Strategy and Leadership 38(4): 17-26.

Jory SR, Benamrauni A, Boojihawon DR, Madichie NO. 2016. Net present value analysis and the wealth creation process: a case illustration. The Accounting Educators Journal 26(1): 86-99.

Juanda B. 2009. Metodologi Penelitian Ekonomi dan Bisnis. Bogor: IPB Press.

Jumingan. 2009. Analisa Laporan Keuangan. Surakarta:Bumi Aksara.

Khairunnisa, Daryanto A, Kirbrandoko. 2018. Strategi pengembangan pengelolaan pasar oleh perusahaan daerah Pasar Pakuan Jaya: Pendekatan Bisnis Model Kanvas. Jurnal Aplikasi Manajemen dan Bisnis (JABM) 5(3):510 Mitchell RC, Agle BR, Wood DJ. 1997. Towards a theory of stakeholder identification and salience: defining the principle of who and what really counts. Academic of Management Review 22: 835-896.

Nurhakim AS, Suparno O, Nurrochmat DR. 2018. Pengembangan model bisnis dan strategi pelayanan kesehatan. Jurnal Aplikasi Bisnis dan Manajemen (JABM) 4(2):251

Osterwalder A, Pigneur Y. 2015. Business Model Generation. New Jersey: John Wiley \& Sons, Inc.

Puspatara Putu SP. 2015. Tinjauan terhadap kebijakan pengelolaan pasar rakyat di Provinsi DKI
Jakarta dalam menghadapi persaingan dengan pasar modern. Jurnal Ilmiah Universitas Bakrie 3(3): 1

Rokhmawati A. 2019. Interest rate risk of banking sector: the effect of maturity gap on net interest income in Indonesia. Journal of Economic, Finance and Accounting 6(1) : 19-31.

Shody A, Noerwasito VT, Setijanti P. 2019. Evaluation of revitalization strategy: a case study of Barukoto Traditional Market in Bengkulu, Indonesia. International Journal of Engineering Research and Advanced Technology 5(2): 20-38.

Sidrauruk D, Giatman M, Murad MS. 2018. Analisis kelayakan investasi menggunakan metoda Discounted Cash Flow Tambang Galena PT. Triple Eight Energy, Kecamatan Koto Parik Gadang Diateh Kabupaten Solok Selatan Provinsi Sumatera Barat. Jurnal teknik UNP. 1(1): 1-19.

Soeherman B. 2014. Lasting Lean : ReInnovate Your Business Model Better, Faster, and Easier!. Jakarta: PT Alex Media Computindo.

Sulistyo H. 2011. Implementasi QFD dalam meningkatkan daya saing pasar trasdisional. Jurnal Siasat Bisnis 15(2): 157-169.

Sudjono R. 2014. Kesesuaian Revitalisasi pasar tradisional menjadi pusat perbelanjaan. E-Journal Graduate Unpar 1(2):198.

Suryadarma D, Poesoro A, Budiyati S, Akhmadi, Rosfadhila M. 2007. Dampak Supermarket Terhadap Pasar Dan Pedagang Ritel Tradisional Di Daerah Perkotaan di Indonesia. Jakarta: Lembaga Penelitian SMERU.

Viali AF, Rifin A, Saptono IT. 2018. Strategi pengembangan bisnis cargo PT. Garuda Indonesia, Tbk dengan pendekatan business model canvas. Jurnal Aplikasi Bisnis Dan Manajemen (JABM) 4(3):474.

Wiska F. 2016. Business model canvas Sekolah Peternakan Rakyat di Kecamatan Kedungadem Kabupaten Bojonegoro [tesis]. Bogor: Institut Pertanian Bogor.

Zahratain I, Anggraeni L. 2015. Dampak perkembangan toko modern terhadap kinerja pedagang produk pertanian pada pasar tradisional di Kota Bekasi. Jurnal Manajemen \& Agribisnis 11(2):119-128. 